\title{
The Emergence of a New Mutant Superbacteria: The Fight Continues
}

\section{Baharudin Abdullah*}

Department of Otorhinolaryngology - Head and Neck Surgery, School of Medical Sciences, Universiti Sains Malaysia, 16150 Kubang Kerian, Kelantan, Malaysia

Just as we thought that we have managed to conquer and win the fight against our arch enemy the hostile microbes, we were suddenly ambushed by the discovery of a new emergent mutant microbes "NDM-1" superbug.

NDM-1 (or New Delhi metallo-beta-lactamase) is a gene mutation that was found in many common and harmful bacteria like E. coli and Klebsiella pneumoniae with a resistance that can even withstand the latest generation of antibiotics, the antibiotics that were used as a last resort when more common drugs have no effect [1].

The development of antimicrobials over the years has contributed to a better treatment of infection and the eradication of the pathogens. As evidenced by the numerous clinical trials, their actions are rapid and efficacious in eradicating the microorganisms based on the susceptibility of the microorganisms to the respective antimicrobials.

It is common practice for example to use antibiotic in surgical procedures. Broad-spectrum empirical regimens employed include the combination of a $1^{\text {st }}$ or $2^{\text {nd }}$ generation cephalosporin plus clindamycin or metronidazole (depending on the severity of the condition) [2]. Cefepime and cefpirome are new $4^{\text {th }}$ generation parenteral cephalosporins with a spectrum of activity which makes them suitable for the treatment of infections caused by a wide variety of bacteria. They are effective against both gram-positive and gram-negative organisms, including Staphylococcus aureus and Pseudomonas aeruginosa with activity comparable to or greater than that of cefotaxime or ceftazidime respectively [2].

In randomized clinical trials in hospitalized patients with generally moderate to severe community-acquired or nosocomial pneumonia, cefepime monotherapy exhibited good clinical and bacteriological efficacy [3]. Importantly, cefepime is stable against many of the common plasmid- and chromosome-mediated beta-lactamases and is a poor inducer of AmpC beta-lactamases. As a result, it retains activity against Enterobacteriaceae that are resistant to third-generation cephalosporins, such as mutants of Enterobacter spp [3].

However, the spread of metallo- $\beta$-lactamases poses a major challenge both for treatment of patients and for policies of infection control thus exposing the substantial unpreparedness of public health structures in facing up to this challenge. Metallo- $\beta$-lactamases are resistance determinants of increasing clinical relevance in Gramnegative bacteria and due to their broad range, potent carbapenemase activity and resistance to inhibitors, these enzymes can confer resistance to almost all $\beta$-lactams [4]. Some metallo- $\beta$-lactamases encoded by mobile DNA have emerged in important Gram-negative pathogens for example Enterobacteriaceae and Pseudomonas aeruginosa. Their enzymes,VIM-1 and NDM-1 have been involved in the recent outbreak resulting from the international dissemination of antibiotic resistant enterobacteria [4].

With the discovery of mutant and new resistant microbes, new strategy may have to be adopted and implemented. The answer may lie in pharmacogenomics. Pharmacogenomics is the branch of pharmacology which deals with the influence of genetic variation on drug response in patients by correlating gene expression or singlenucleotide polymorphisms with a drug's efficacy or toxicity [5]. Thus, pharmacogenomics is a science that examines the inherited variations in genes that dictate drug response and explores the ways these variations can be used to predict the response of patients to drugs whether good, bad or no response at all.

Research in this area maybe relatively new but the realisation is dawning that this maybe the way forward in better understanding of the microcosm's universe. Instead of the standard trial and error method of matching patients with the right drugs, medical practitioners will be able to analyze a patient's genetic profile and prescribe the best available drug therapy. Not only the right drug will be used but it will also speed recovery time and increase safety as the likelihood of adverse reactions is eliminated. Pharmaceutical industries will be able to create drugs based on the proteins, enzymes, and RNA molecules associated with genes and diseases. This will facilitate drug discovery and allow drug makers to produce a therapy more targeted to specific diseases. The accuracy will maximize therapeutic effects and also decrease damage to nearby healthy cells. Furthermore, pharmacogenomics has the potential to dramatically reduce the estimated 100,000 deaths and 2 million hospitalizations that occur each year in the United States as the result of adverse drug response [6].

\section{References}

1. Kumarasamy KK, Toleman Ma, Walsh TR, Bagaria J, Butt F, et al. (2010) Emergence of a new antibiotic resistance mechanism in India, Pakistan, and the UK: a molecular, biological, and epidemiological study. Lancet Infect Dis 10: 597-602.

2. Cornaglia G, Giamarellou H, Rossolini GM (2011) Metallo- $\beta$-lactamases: a last frontier for $\beta$-lactams? Lancet Infect Dis 11: 381-393.

3. Chapman TM, Perry CM (2003) Cefepime: a review of its use in the management of hospitalized patients with pneumonia. Am J Respir Med 2: 75-107.

4. Giamarellou H (1999) Fourth generation cephalosporins in the antimicrobial chemotherapy of surgical infections. J Chemother 11: 486-493.

5. Wang L (2010) Pharmacogenomics: a systems approach. Wiley Interdiscip Rev Syst Biol Med 2: 3-22.

6. Lazarou J, Pomeranz BH, Corey PN (1998) Incidence of adverse drug reactions in hospitalized patients: a meta-analysis of prospective studies. JAMA 279: 1200-1205.

*Corresponding author: Baharudin Abdullah, Department of OtorhinolaryngologyHead and Neck Surgery, School of Medical Sciences, Universiti Sains Malaysia, 16150 Kubang Kerian, Kelantan, Malaysia, Tel: +6097676416; Fax: +6097676424; E-mail: baharudin@kb.usm.my, profbaha@gmail.com

Received January 20, 2012; Accepted January 21, 2012; Published January 24 2012

Citation: Abdullah B (2012) The Emergence of a New Mutant Superbacteria: The Fight Continues. J Pharmacogenom Pharmacoproteomics 3:e111. doi:10.4172/2153-0645.1000e111

Copyright: () 2012 Abdullah B. This is an open-access article distributed under the terms of the Creative Commons Attribution License, which permits unrestricted use, distribution, and reproduction in any medium, provided the original author and source are credited. 